\title{
Caracterização morfológica, determinação do nível de ploidia e viabilidade do pólen de uma progênie de tangerineira 'Clementina Fina' e 'Montenegrina'
}

\author{
Roberto Luis Weiler (1); Eduardo Cesar Brugnara (1,2); Divanilde Guerra ('); \\ Maria Teresa Schifino-Wittmann (1); Sergio Francisco Schwarz $\left({ }^{1 *}\right)$ \\ (') Universidade Federal do Rio Grande do Sul (UFRGS), Faculdade de Agronomia, Programa de Pós-Graduação em Fitotecnia, \\ Av. Bento Gonçalves, 7712, 91540-000 Porto Alegre (RS). \\ (2) Empresa de Pesquisa Agropecuária e Extensão Rural de Santa Catarina, Centro de Pesquisa para Agricultura Familiar, \\ Caixa Postal 791, 88965-970 Chapecó (SC). \\ (*) Autor correspondente: schwarz@ufrgs.br
}

Recebido: 16/set./2010; Aceito: 4/mar./2011

Resumo

As plantas cítricas possuem ampla variação morfológica e citogenética. Neste contexto, análises dessas plantas podem auxiliar na identificação de materiais mais promissores para cruzamentos. Uma população de tangerineiras híbridas oriundas do cruzamento das tangerineiras 'Clementina Fina' (Citrus clementina Hort. ex Tan.) e 'Montenegrina' (Citrus deliciosa Ten.) foi avaliada segundo características morfológicas, época de maturação, número cromossômico e viabilidade de pólen. Foi possível distinguir as 94 plantas da progênie e os genitores através dos dados morfológicos. Verificou-se uma alteração no período de maturação dos frutos nas plantas híbridas. Todas as plantas avaliadas são diplóides com um número cromossômico de 2n=18, bem como, alto grau de viabilidade de pólen, variando entre 79,0\% e 98,1\%.

Palavras-chave: Citrus, marcadores morfológicos, número cromossômico, viabilidade do pólen.

\section{Morphological characterization, determination of ploidy level and pollen viability of a progeny of tangerines 'Clementina Fina' and 'Montenegrina'}

\section{Abstract}

Citrus plants show morphological and cytogenetic variability and these characteristics can be useful to identify the materials for hybridization. A population of hybrid tangerines, originated from the cross between 'Clementina Fina' (Citrus clementina Hort. ex Tan.) as female and 'Montenegrina' (Citrus deliciosa Ten.) as male parents, was characterized using morphological traits, maturation period, chromosome number and pollen viability. It was possible to distinguish the 94 plants of the progeny and the parents by morphological traits. The time of fruit ripening of the hybrid extended from the beginning of April until the end of August. All plants analyzed are diploid with a chromosome number of $2 n=18$ and presented high pollen viability, varying from $79.0 \%$ to $98.1 \%$.

Key words: Citrus, morphological markers, chromosome number and pollen viability.

\section{INTRODUÇÃO}

A citricultura é o principal cultivo frutícola mundial. Em 2007, a produção mundial foi de, aproximadamente, 110 milhóes de toneladas, sendo o Brasil responsável por cerca de $19 \%$, com aproximadamente 21 milhóes de toneladas (FAO, 2009). As tangerinas são responsáveis por cerca de $6 \%$ da produção nacional (IBGE, 2008), sendo o Rio Grande do Sul o terceiro maior Estado produtor.

Apesar de serem muito utilizados comercialmente, os citros possuem taxonomia muito complexa, prin- cipalmente com relação ao número de espécies que constituem o gênero Citrus e gêneros relacionados. A dificuldade de se obter um sistema de nomenclatura para o gênero Citrus deve-se, principalmente, à facilidade de hibridação interespecífica e intergenérica, resultando em híbridos férteis ou parcialmente férteis; à frequência com que ocorre poliembrionia neste grupo e à ocorrência da apomixia em muitas espécies (DAVIES e Albrigo, 1994).

As plantas cítricas pertencem à família Rutaceae, subfamília Aurantioideae, geralmente são diplóides, com $2 \mathrm{n}=2 \mathrm{x}=18$ cromossomos, mas também ocor- 
rem triplóides, $2 \mathrm{n}=3 \mathrm{x}=27$ cromossomos, e tetraplóides, 2n=4x=36 cromossomos (Koller, 1994; Guerra et al., 1997). Desta subfamília, o gênero Citrus é o mais importante economicamente, com alta diversidade de espécies, cultivares e clones. A variabilidade genética em Citrus é relacionada, além do alto número de unidades taxonômicas (espécies e híbridos), à ocorrência frequente de mutaçōes somáticas que resultam em variaçôes, a partir das brotaçôes onde ocorreram (Coletta Filho et al., 1998). Os estudos com grão de pólen podem contribuir, por exemplo, para a taxonomia (Rodrigues et al., 1999), mas são especialmente importantes para determinação da fertilidade masculina (AgARWAL, 1989).

Caracteres como a estrutura da planta, flores, frutos e folhas são utilizados por diversos autores para descrever e caracterizar variedades distintas de tangerineiras e híbridos (Domingues et al., 1999). A caracterização morfológica consiste na adoção de descritores botânicos herdáveis, facilmente visíveis e mensuráveis, que, a princípio, são expressos em todos os ambientes (IBPGR, 1988). Esse tipo de análise é mais simples e de menor custo, embora com limitaçóes relacionadas aos caracteres que representam herança aditiva, os quais são altamente influenciados pelo ambiente, e às cultivares com grande semelhança fenotípica (Oliveira et al., 2000). Mesmo assim essa técnica é utilizada internacionalmente, conseguindo, em certos casos, discriminar até mesmo materiais vegetais, que não são passíveis de discriminação através de marcadores bioquímicos ou moleculares.

A citogenética compreende o estudo relativo ao cromossomo isolado ou em conjunto, condensado ou distendido, no que diz respeito à morfologia, organização, função e replicação bem como sua variação e evoluçâo (Guerra, 1988).

A citogenética assume papel importante em programas de melhoramento genético de plantas, pois através dos estudos citogenéticos é possível determinar o número cromossômico, nível de ploidia, comportamento cromossômico na meiose e na mitose, fertilidade do grão de pólen, auxiliando na identificação de materiais que possam ser utilizados em cruzamentos dirigidos (SYBENGA, 1993; 1998).

Na primavera de 1993, foram realizados cruzamentos entre as tangerineiras cv. Clementina Fina (Citrus clementina Hort. ex Tan.) e cv. Montenegrina (Citrus deliciosa Ten.), através de polinização dirigida. As sementes obtidas dos cruzamentos foram colhidas e cultivadas em 1994 através de semeadura in vitro em laboratório. Não foram realizados testes para confirmaçáo de paternidade, pois a tangerineira Clementina Fina é monoembriônica, sendo os cruzamentos controlados com emasculação na fase que as flores estavam em botáo com mais de $8 \mathrm{~mm}$ de diâmetro (em pré-antese), polinização com pólen do genitor masculino desejado e ensacamento individual de cada flor por dez dias para evitar contaminação com polens de ou- tras plantas trazidos pelo vento ou por insetos. $\mathrm{O}$ pólen utilizado veio de flores que haviam sido ensacadas antes de sua abertura e foi coletado no momento da polinização a partir de flores plenamente abertas. No ano de 1995 as respectivas mudas foram para o campo, no total de 94 plantas. As plantas permaneceram de "pé franco", ou seja, não foram enxertadas, para que o porta-enxerto não fosse responsável por imprimir as suas características e mascarar as características dos híbridos.

O presente trabalho teve como objetivo determinar as características morfológicas e citogenéticas da populaçáo de 94 plantas de tangerineiras híbridas de 'Clementina Fina' (Citrus clementina Hort. ex Tan.), como genitor feminino e 'Montenegrina' (Citrus deliciosa Ten.), como genitor masculino.

\section{MATERIAL E MÉTODOS}

As 94 plantas utilizadas neste estudo, mais as plantas genitoras 'Clementina Fina' (Citrus clementina Hort. ex Tan.) e 'Montenegrina' (Citrus deliciosa Ten.), estáo localizadas no município de Eldorado do Sul, Rio Grande do Sul, Brasil, à latitude de 30²9'S e longitude de 510. Para a caracterização morfológica dos híbridos, as plantas foram analisadas, em 2005, quanto a formato, altura, densidade de ramos, diâmetro do tronco, comprimento e formato dos espinhos, de acordo com o descrito no International Board for Plant Genetic Resources (IBPGR, 1988) (Figura 1). As folhas, no total de 20 por planta, coletadas cinco em cada quadrante, foram analisadas quanto ao tipo, cor, comprimento de pecíolo em relaçáo ao limbo, pecíolo alado, forma do pecíolo, forma do limbo, formato da margem, comprimento total (limbo mais pecíolo) e largura. As características avaliadas nos frutos foram forma, formato da base, formato do ápice, superfície da casca, aderência do epicarpo ao mesocarpo, visibilidade das glândulas de óleo, cor do mesocarpo (albedo), aderência entre gomos, número de sementes, número de gomos por fruto, peso, altura e diâmetro. Foram avaliados 10 frutos por planta, sendo coletados cinco frutos de cada lado das plantas da linha.

Os dados obtidos foram analisados utilizando-se o sistema de taxonomia numérica e multivariada 'Numerical Taxonomic and Multivariate Analisis System' (NTSYS) - versão 2.1 (RohlF, 2000). Foi utilizada a metodologia de análise de mediçôes qualitativas e quantitativas misturadas proposta por Gower (1971), através do programa 'Multiv' dados são transformados para então serem transportados para o programa (NTSYS). Um dendograma foi construído pelo método de agrupamento através da média aritmética 'Unweighted Pair Gruop Method with Aritmetic Avarage' (UPGMA).

Avaliou-se a época de maturação dos frutos das plantas que produziram (80 plantas) de 2003 a 2005. Foram 
considerados dentro do padrão de comercializaçấo, os que tinham, no mínimo, $40 \%$ de suco do volume total, e relação entre a quantidade de sólidos solúveis totais e a acidez total titulável (SST/ATT) entre 8 e 16 (SARTORI et al., 1998). Os frutos foram coletados quinzenalmente a partir da data em que iniciavam a mudança de cor da casca. As análises de suco foram feitas em até três dias após a data de colheita, sendo os frutos mantidos em câmara de conservaçáo à temperatura em torno de $4{ }^{\circ} \mathrm{C}$. O suco foi extraído com espremedor elétrico e a massa de suco determinada pela diferença entre a massa total de cada amostra de frutos e a massa do bagaço. A porcentagem de suco foi determinada relacionando a massa de suco extraído com a massa de cada amostra. O teor de SST foi obtido por refratometria (modelo 2WAJ ABBE REFRATOMETER). A leitura obtida foi expressa em porcentagem (\%) de sólidos solúveis totais no suco. A acidez total titulável (ATT) foi avaliada por titulação com hidróxido de sódio $(\mathrm{NaOH})$, até $\mathrm{pH} 8,1$, empregando-se uma amostra de 6 $\mathrm{ml}$ de suco diluído em água destilada $(50 \mathrm{ml})$. Utilizou-se um medidor de $\mathrm{pH}$ (Digimed DM-20), provido de um termocompensador. $\mathrm{O}$ cálculo do teor de acidez foi realizado utilizando-se a seguinte fórmula $\mathrm{A}=(\mathrm{V} \times \mathrm{N} x$ $0,064 \times 100) / G$ (AoAC, 2002), em que $A=$ acidez total em gramas \% de ácido cítrico; $\mathrm{V}=$ volume de hidróxido de sódio gasto na titulaçáo, em $\mathrm{ml} ; \mathrm{N}=$ normalidade do $\mathrm{NaOH} ; 0,064$ = fator para expressar a acidez em ácido cítrico, em mEq; $\mathrm{G}=$ massa da amostra. A relação SST/ ATT foi obtida a partir das determinaçóes anteriormente realizadas para sólidos solúveis totais (SST) e para acidez titulável total (ATT).

Para o desenvolvimento das análises citogenéticas foram coletados botôes florais entre 2 e $9 \mathrm{~mm}$, os menores para análise de número cromossômico em células-mãede-pólen e os maiores para estimar a viabilidade dos grãos de pólen (Rodrigues et al., 1999), das 52 plantas da progênie que floresceram em 2004. A fixação foi feita imergindo os botóes florais imediatamente, no campo, em solução à base de três partes de álcool etílico absoluto e uma parte de ácido acético glacial. Os frascos foram mantidos em temperatura ambiente por 24 horas; após esse período o material foi transferido para álcool $70 \%$ e mantido sob refrigeração até a análise.

Para a determinação do número cromossômico, a partir dos botôes florais com diâmetro de 2 a $3 \mathrm{~mm}$, as anteras foram separadas, partidas e coradas com carmim propiônico $2 \%$, esmagando-se o material com espátula, colocando-se a lamínula e pressionando-a a fim de permitir bom espalhamento dos cromossomos. As fases que tiveram especial atenção para as configurações cromossômicas foram a metáfase I e disjunção em anáfase I e II.

Para a análise de viabilidade dos grãos de pólen, foram utilizados botôes florais com diâmetro superior a $8 \mathrm{~mm}$ e as lâminas, confeccionadas com as anteras de dois botôes, as quais foram coradas com carmim propiônico $2 \%$. Fo-
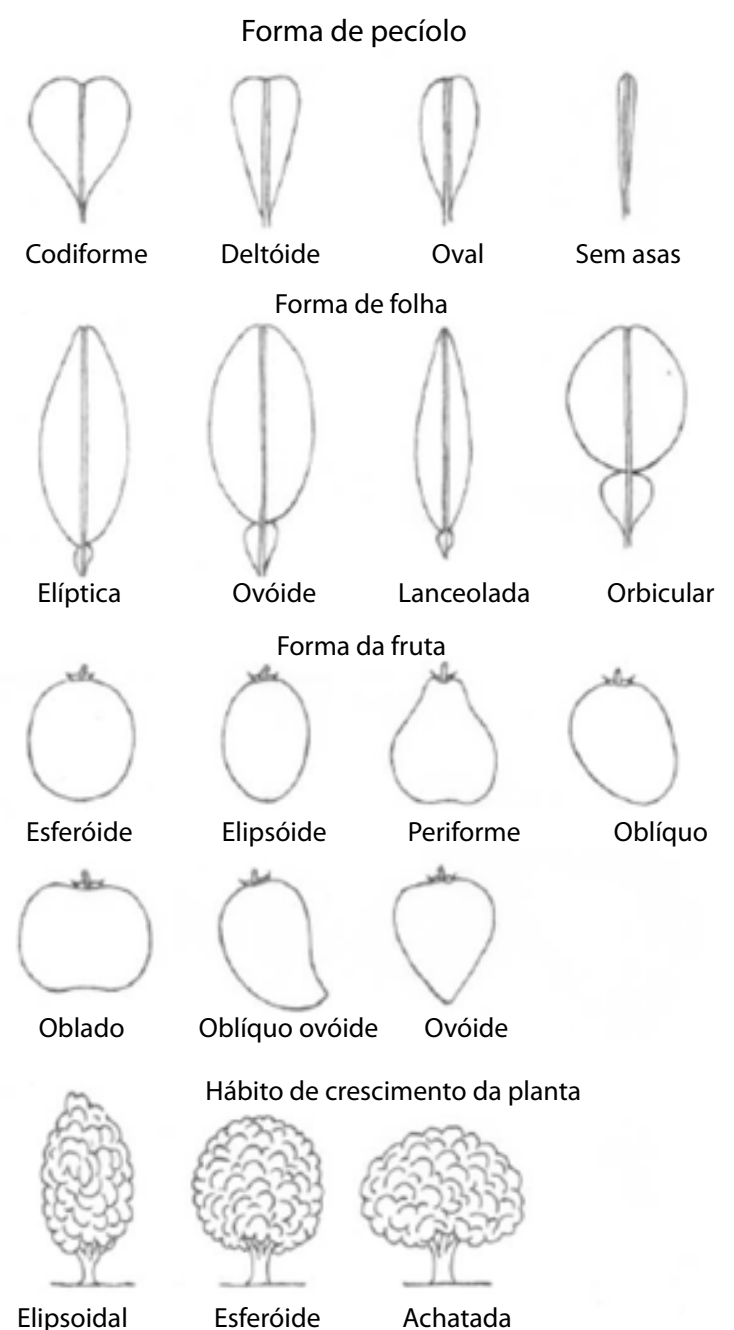

Elipsoidal

Achatada

Figura 1. Exemplos de descritores morfológicos utilizados nas avaliaçôes de uma populaçáo de híbridos oriunda do cruzamento entre as tangerinerineiras 'Clementina Fina' e 'Montenegrina'. (Adaptado de IвPGR, 1988).

ram avaliadas quatro lâminas por planta, com contagem mínima de 1000 grãos de pólen por planta, considerando-se como férteis os grãos cheios e bem corados, e como estéreis os enrugados e/ou incolores. Avaliou-se também a incidência de grãos de pólen maiores, chamados de macropolens, os quais poderiam ser indícios de gametas não reduzidos $(2 n)$.

\section{RESULTADOS E DISCUSSÃO}

Quanto às características morfológicas, observou-se 41\% das plantas o formato elipsóide, $54 \%$ esferóide e $5 \%$ eram achatadas ('Clementina Fina' e 'Montenegrina' - formato esferóide); quanto à densidade de ramos, em $8 \%$ das plantas tinham ramos esparsos e $92 \%$ ramos densos ('Clementina Fina' e 'Montenegrina' - ramos densos). A altura variou de 1,30 (plantas E07) a 4,10 m (planta G01) 
('Clementina Fina' - 3,2 m e 'Montenegrina' - 2,4 m), e quanto à circunferência do tronco, as plantas tinham de 15,0 (planta F04) a 46,5 cm (planta F31) ('Clementina Fina' - $34 \mathrm{~cm}$ e 'Montenegrina' - $28 \mathrm{~cm}$ ).

O comprimento médio dos espinhos variou de 1,0 a $4,59 \mathrm{~cm}$ (plantas E29 e G35 respectivamente); nas plantas E17, F04 e G14 não havia espinhos, mesmo sendo de "pé franco". Em todas as plantas com espinhos, os mesmos tiveram formato retilíneo.

Analisando o tipo de folha, em todas as plantas notaram-se folhas simples, o que é uma característica das tangerineiras, além de pecíolo curto em relação ao comprimento da folha, e não alado. Para cor, $14 \%$ das plantas tinham folhas com coloração verde clara, $54 \%$ verde e $32 \%$ verde escuras ('Clementina Fina' - verde- clara e 'Montenegrina' - verde).

Quanto ao formato das folhas, em 76\% das plantas observaram-se folhas elipsóides, $9 \%$ ovóides, $2 \%$ circulares e 13\% lanceoladas ('Clementina Fina' - elipsóide e 'Montenegrina' - lanceolada). Quanto à borda, 66\% das plantas tinham folhas com as bordas dentadas, $7 \%$ lisas e $27 \%$ com as bordas onduladas ('Clementina Fina' - ondulada e 'Montenegrina' - dentada). Quanto ao comprimento, as médias das folhas variaram de 4,57 até 14,48 cm ('Clementina Fina' - 7,87 cm e 'Montenegrina' - 7,24 $\mathrm{cm})$. Quanto à largura foram encontradas folhas com média de 1,61 até 4,39 cm, nas plantas E07 e G36 respectivamente ('Clementina Fina' - 2,97 cm e 'Montenegrina' $-2,42 \mathrm{~cm})$.

Quanto aos frutos, 40\% eram de formato esferóide e $60 \%$ achatado ('Clementina Fina' - esferóide e 'Montenegrina' - achatado); $35 \%$ com base achatada, $35 \%$ convexa e 30\% mamiliforme ('Clementina Fina' - mamiliforme e 'Montenegrina' - convexo); em 56\% dos frutos analisados ápices eram retilíneos e $44 \%$ convexos ('Clementina Fina' - retilíneo e 'Montenegrina' - convexo); 58\% tinham casca lisa, $40 \%$ levemente rugosa e $2 \%$ rugosa ('Clementina Fina' e 'Montenegrina' - casca lisa); $45 \%$ dos frutos possuía aderência mínima do mesocarpo ao endocarpo, 38\% moderada e 17\% firme, ('Clementina Fina' - moderada e 'Montenegrina' - mínima) implicando esta variável na facilidade de descascar a tangerina; em 45\% dos frutos as glândulas de óleo da casca estavam quase imperceptíveis, $42 \%$ visíveis e $13 \%$ salientes ('Clementina Fina' e 'Montenegrina'- glândulas de óleo da casca quase imperceptíveis).

Em todas as plantas avaliadas o mesocarpo (albedo) era da cor branca; $45 \%$ dos frutos tinham mínima aderência entre gomos, 50\% aderência moderada e 5\% alta ('Clementina Fina' - aderência moderada e 'Montenegrina' - aderência mínima); o número médio de gomos por fruto variou de 8,4 a 12,0 para as plantas F43 e F39 respectivamente ('Clementina Fina' - 9,5 e 'Montenegrina' - 9,2); o número médio de sementes ficou entre 1,0 e 33 sementes por fruto para as plantas E 21 e F38 respectiva- mente ('Clementina Fina' - 9,2 e 'Montenegrina' - 10,4). É importante destacar que as plantas não estão isoladas de outros pomares podendo ocorrer polinização cruzada. A massa média dos frutos ficou entre 42,6 e 165,8 g, para as plantas G22 e E14 respectivamente ('Clementina Fina' 97,3 g e 'Montenegrina' - 81,7 g); o diâmetro dos frutos ficou entre 3,71 e 7,20 cm, para as plantas F15 e F20 respectivamente ('Clementina Fina' - 6,32 cm e 'Montenegrina' $-5,26 \mathrm{~cm}$ ) e a altura dos frutos ficou entre $2,82 \mathrm{e}$ $6,23 \mathrm{~cm}$, para as plantas F15 e F30 respectivamente ('Clementina Fina' - 5,24 cm e 'Montenegrina' - 4,35 cm).

A partir de todos os dados morfológicos analisados, foi construído um dendograma de similaridade (Figura 2). Neste agrupamento observa-se que as plantas E09, E19, E18, E28, G30, G36, G39 e F25 foram as que ficaram mais próximas morfologicamente ao genitor masculino 'Montenegrina', com uma similaridade de 36 a $45 \%$. A planta E20 é a que mais se assemelha ao genitor feminino 'Clementina Fina', mesmo assim somente com uma similaridade em torno de 37\%. As plantas F06, G01 e G14 formaram um grupo que se distingue de todas as outras plantas, tendo uma similaridade com o restante do grupo de apenas $25 \%$. A similaridade média do grupo foi muito baixa, em torno de $35 \%$. Foi possível uma distinção de todas as plantas através de marcadores morfológicos.

A distinção de plantas por características morfológicas é essencial para uma nova cultivar ou cultivar essencialmente derivada ser submetida à proteção. Para fins de proteção varietal, a nova cultivar deve atender a três requisitos básicos, ou seja, ser distinta, homogênea e estável (DHE) (Bernet et al., 2003, Carvalho et al., 2009), atendendo aos requisitos dispostos na Lei ${ }^{\circ} 9.456$, de 25 de abril de 1997. A distinção dos genótipos é realizada por meio de marcadores morfológicos, sendo avaliados marcadores fenotípicos conforme os descritos neste trabalho.

Segundo Domingues et al. (1999) caracteres como a estrutura da planta, flores, frutos e folhas são utilizados para descrever e caracterizar variedades distintas de tangerineiras e híbridos. Estas características foram eficientes na avaliação de 37 cultivares de tangerineiras em trabalho desenvolvido por KoeHLer-SAntos et al. (2003).

A caracterização morfológica é uma análise simples e de menor custo, embora com limitaçôes relacionadas aos caracteres que têm herança quantitativa, os quais são altamente influenciados pelo ambiente e pelas cultivares com grande semelhança fenotípica (Oliveira et al., 2002). Mesmo assim essa técnica é utilizada internacionalmente, conseguindo, em certos casos, discriminar até mesmo materiais vegetais, que não são passíveis de discriminação através de marcadores bioquímicos ou moleculares. Os resultados constantes deste estudo permitiram a distinção de todas as plantas, e em se tratando de material com boas características permitiria a sua distinção para fins de proteção varietal. 
Com os dados das análises qualitativas dos frutos foi determinada a época de maturação das 80 plantas da progênie que produziram nos anos de 2003, 2004 e 2005 (Tabela 1). Observou-se que na época de maturação dos 80 híbridos de 'Clementina Fina' e 'Montenegrina' uma amplitude de datas de colheita entre a primeira quinzena de abril e a primeira quinzena de agosto. Sartori et al. (1998) identificaram que o genitor masculino 'Montenegrina' possui uma época de colheita entre agosto e outubro e o genitor feminino 'Clementina Fina', entre abril e maio. Portanto, a época de maturação da progênie se aproximou mais ao do genitor feminino, fato interessante

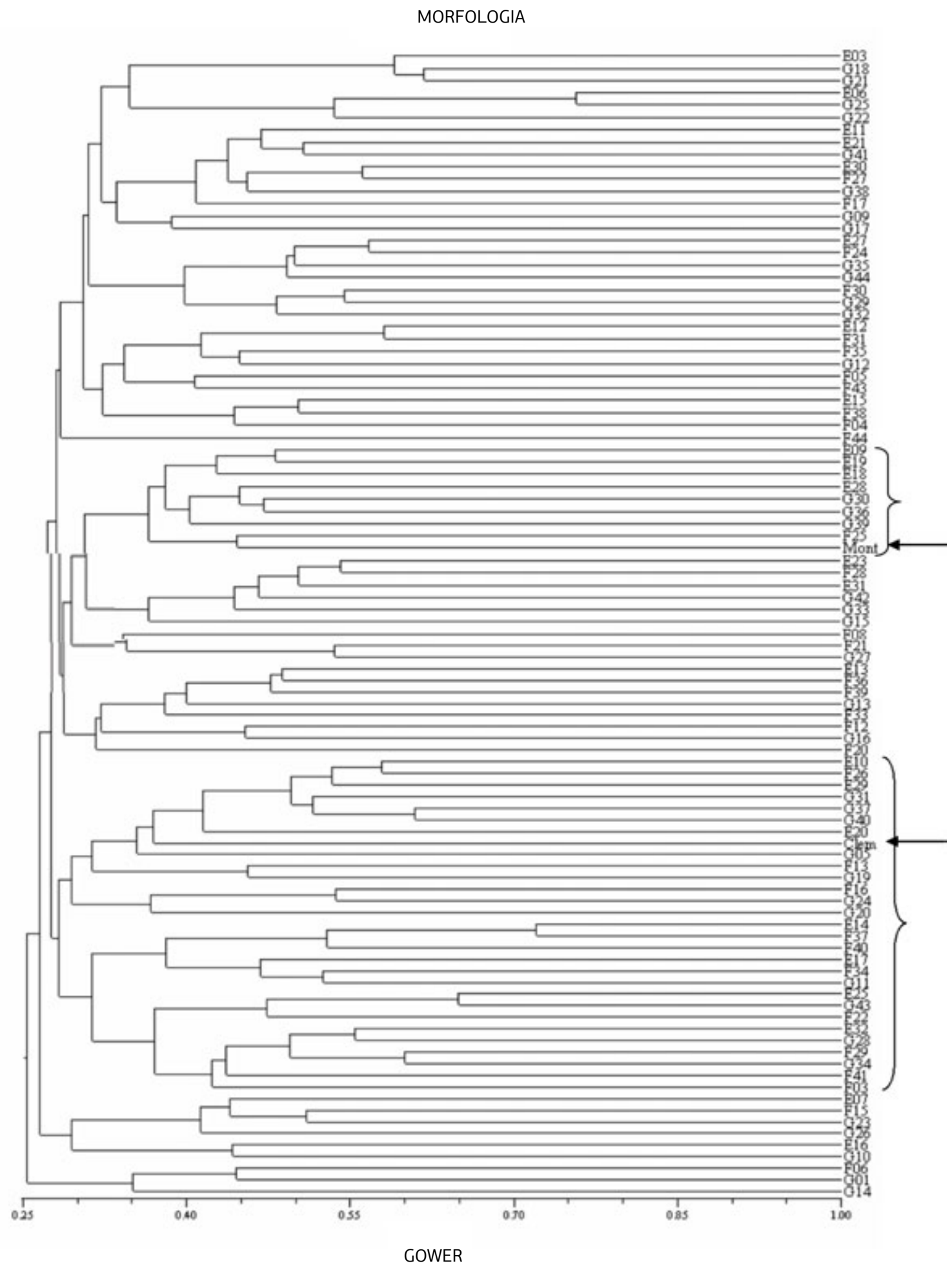

Figura 2. Dendograma com 96 plantas (94 progênies e genitores) oriundas do cruzamento entre as tangerineiras 'Clementina Fina' e 'Montenegrina', gerado através do programa NTSYS, utilizando marcadores morfológicos. As setas no dendograma indicam o genitor feminino 'Clementina Fina' e o genitor masculino 'Montenegrina' e as chaves indicam as plantas nos mesmos grupos dos genitores. 
Tabela 1. Época de maturação de frutos de 80 plantas oriundas do cruzamento das tangerineiras 'Clementina Fina' e 'Montenegrina' as quais produziram frutos nos anos de 2003, 2004 e 2005

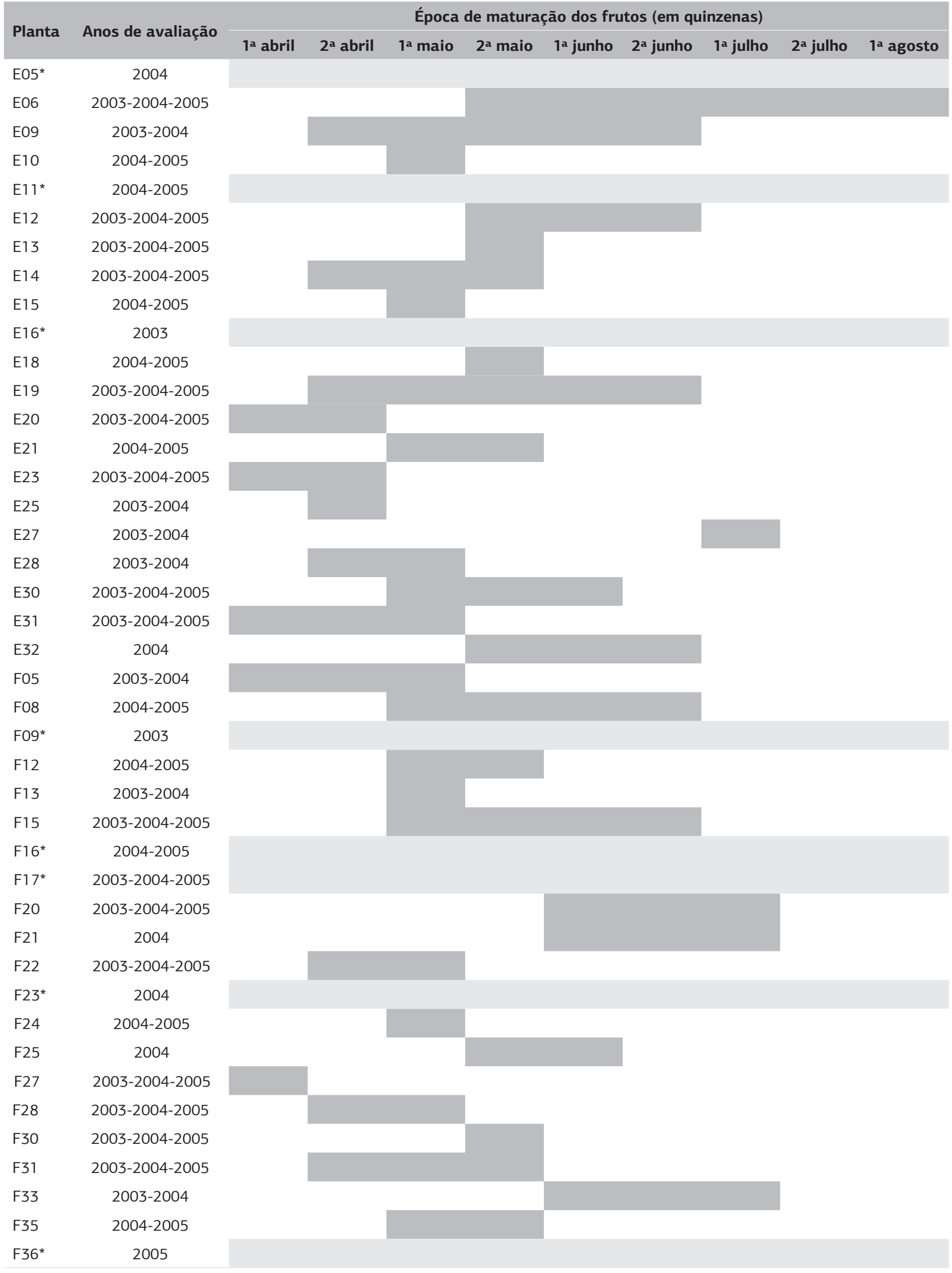


Tabela 1. Conclusão

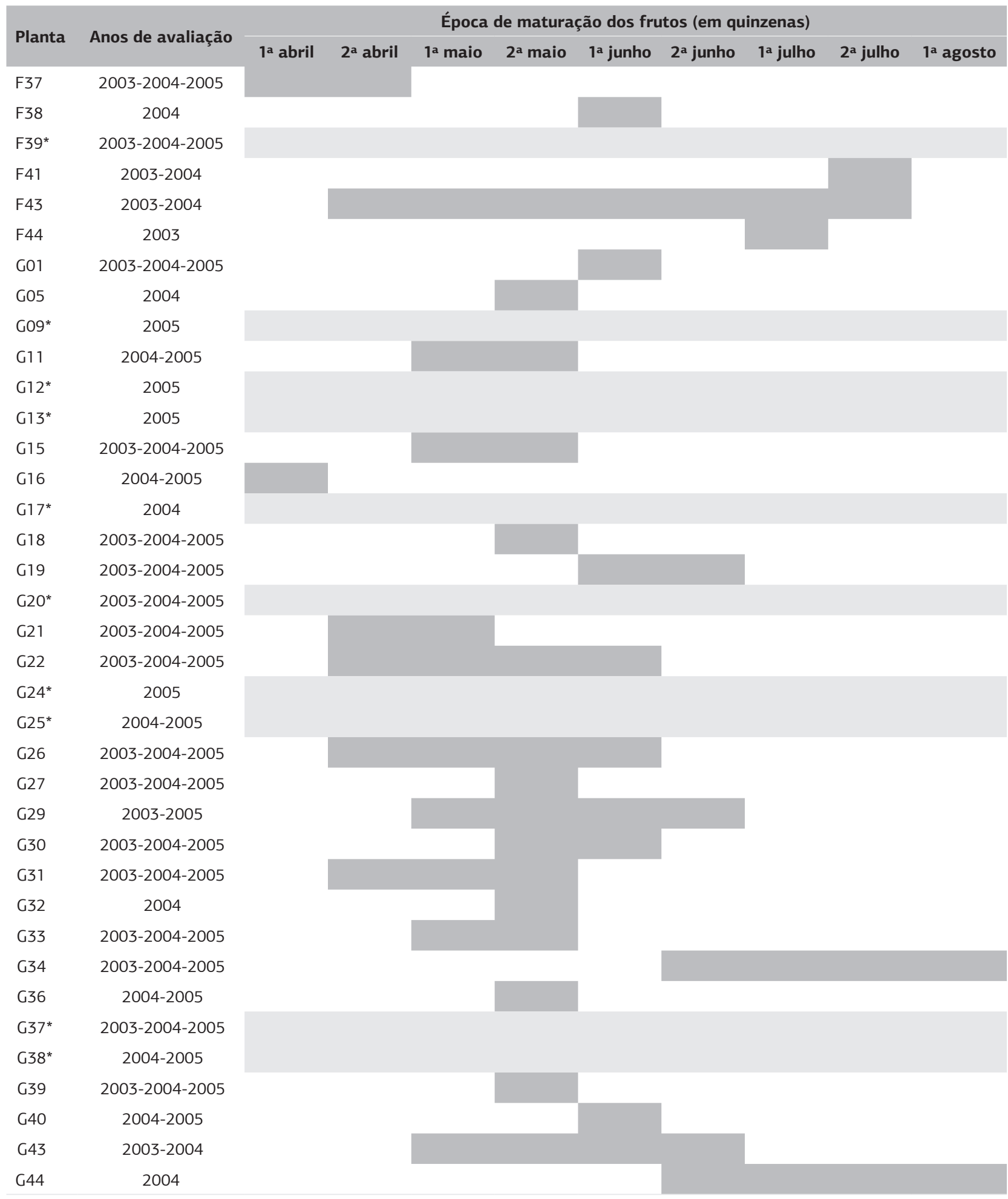

Período com frutos aptos para colheita e comercialização (40\% de suco e SST/AT entre 8 e 12).

Período sem frutos aptos para colheita e comercialização.

* Plantas com frutos que não atingiram índices de maturação próprios para a comercialização. 
para o objetivo de obtenção de frutos aptos à comercialização em épocas distintas da tangerineira 'Montenegrina', já que o procurado neste cruzamento eram híbridos com as características desta, mas com menos sementes e época de maturaçáo distinta, tendo chances de sucesso no mercado consumidor.

Nas análises para a determinação do nível de ploidia, das 52 plantas da progênie que produziram flores em 2004 e seus genitores, observou-se que todas as plantas são diplóides, com número cromossômico x=9, (Figura 3a), corroborando com os resultados obtidos por GUERRA et al. (1997) que caracterizaram como diplóides 51 plantas de Citrus, Poncirus trifoliata e sete híbridos interespecíficos. O número básico de cromossomos de todas as espécies de Citrus, bem como dos gêneros Poncirus e Fortunella é nove, sendo a condição diplóide predominante, embora o número básico de nove cromossomos apareça em algumas variedades, não somente multiplicado por dois, nos diplóides, mas também em maior número, nos poliplóides. A identificação de plantas poliplóides é útil devido ao grande potencial delas no melhoramento de plantas frutíferas (BoRÉM, 2005).
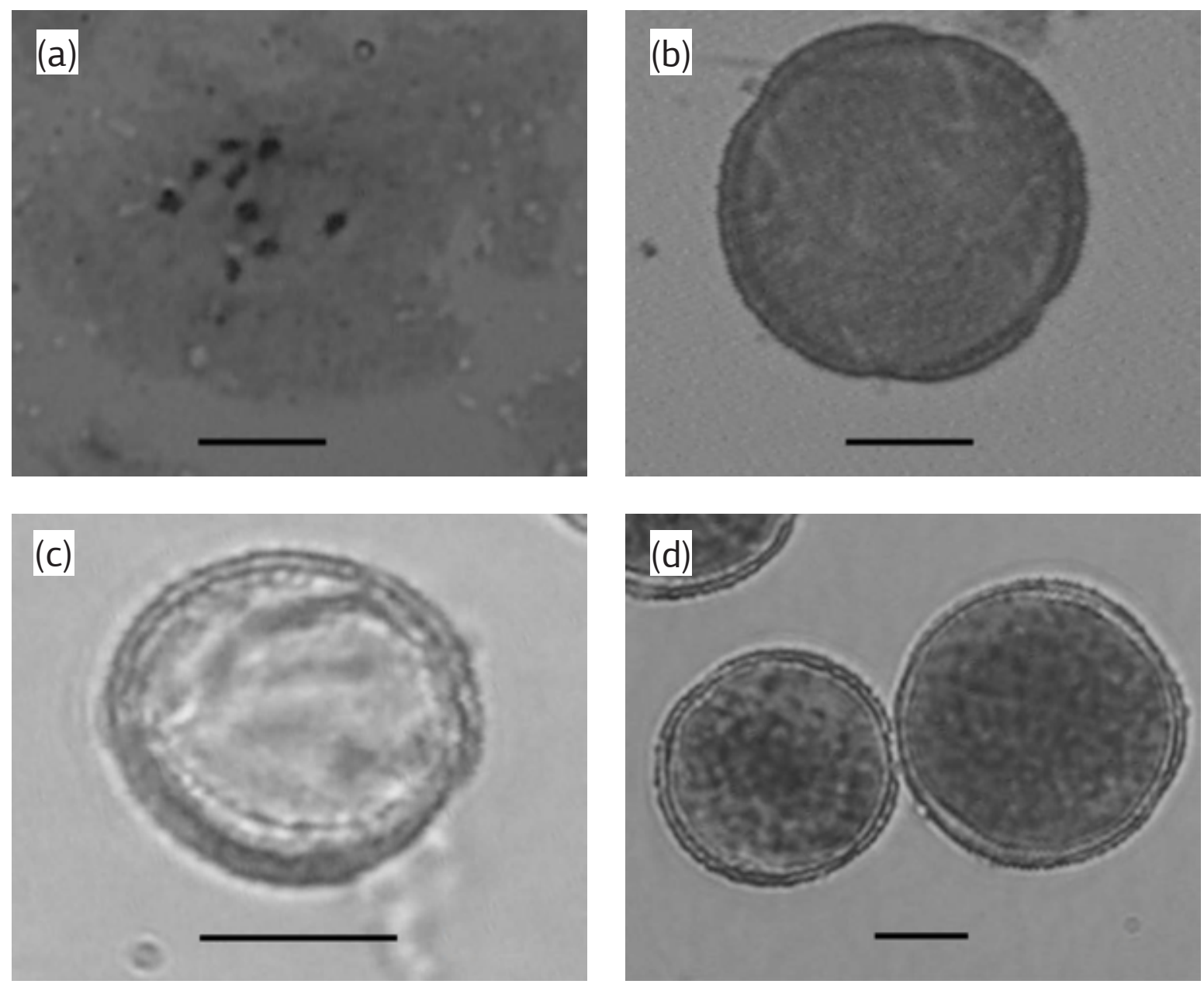

Figura 3. Determinação do nível de ploidia e da viabilidade dos grãos de pólen. a) Diacinese em célula mãe de pólen da planta E19, com 9 bivalentes; b) Grão de pólen viável da planta E19; c) Grão de pólen inviável da planta E06; d) Grão de pólen normal e grão de pólen 'gigante' da planta E06. $($ Escala $=10 \mu \mathrm{m})$. 
Tabela 2. Porcentagem de fertilidade de grãos de pólen de 52 plantas híbridas decorrentes do cruzamento dirigido das tangerineiras 'Clementina Fina' e 'Montenegrina'

\begin{tabular}{|c|c|c|c|c|c|c|c|}
\hline \multicolumn{2}{|c|}{ Fertilidade } & \multicolumn{2}{|c|}{ Fertilidade } & \multicolumn{2}{|c|}{ Fertilidade } & \multicolumn{2}{|c|}{ Fertilidade } \\
\hline Planta & Pólen (\%) & Planta & Pólen (\%) & Planta & Pólen (\%) & Planta & Pólen (\%) \\
\hline E11 & 79,0 & F35 & 92,0 & E18 & 94,9 & G34 & 96,2 \\
\hline G30 & 83,9 & E25 & 92,2 & G40 & 95,1 & G21 & 96,3 \\
\hline E21 & 86,2 & G05 & 92,2 & E14 & 95,2 & G16 & 96,4 \\
\hline E31 & 88,5 & G36 & 92,7 & G18 & 95,4 & G25 & 96,5 \\
\hline G24 & 88,9 & G01 & 93,1 & F30 & 95,5 & G22 & 96,6 \\
\hline E06 & 89,4 & G31 & 93,4 & E20 & 95,5 & F28 & 96,8 \\
\hline G37 & 89,9 & G13 & 93,9 & $\mathrm{~F} 12$ & 95,5 & F27 & 96,9 \\
\hline E19 & 90,6 & E30 & 94,2 & E15 & 95,6 & G20 & 97,0 \\
\hline F24 & 90,8 & G26 & 94,5 & F31 & 95,7 & F16 & 97,0 \\
\hline F15 & 90,9 & F20 & 94,5 & E23 & 95,9 & F05 & 97,8 \\
\hline F17 & 91,3 & F29 & 94,6 & G15 & 96,0 & F22 & 98,0 \\
\hline G27 & 91,6 & E28 & 94,9 & F39 & 96,1 & G12 & 98,1 \\
\hline
\end{tabular}

do pólen em progênies dos cruzamentos de tangerineira 'Montenegrina' $(C$. deliciosa Ten.) com a tangerineira 'King' ( $C$. nobilis Lour.) e com a laranjeira 'Caipira' ( $C$. sinensis (L.) Osb.).

Os estudos com grãos de pólen podem contribuir, por exemplo, para a taxonomia (Rodrigues et al., 1999), mas são especialmente importantes para determinação da fertilidade masculina (Agarwal, 1989). Portanto, como os índices de fertilidade de pólen destas plantas foram elevados, muitas delas poderiam efetivamente ser utilizadas como genitores masculinos em cruzamentos dirigidos. Nestas avaliações foi possível a observação eventual de macropólens corados (grãos de pólen gigantes), em frequência menor que $0,1 \%$, (Figura 3d). Supóe-se que estes sejam grãos não reduzidos, podendo ser muito úteis na produção de plantas poliplóides em cruzamentos (CAvalCANTE et al., 2000). Conforme Simioni et al. (2004) plantas que produzem grãos de pólen com $30 \%$ a $40 \%$ de incremento no tamanho, quando comparados com grãos considerados normais, servem como um indicativo de grãos de pólen não reduzidos. A utilização de plantas boas produtoras de gametas não reduzidos no melhoramento pode levar à geração de plantas com níveis de ploidia mais elevados, o que pode ser muito vantajoso para algumas características como, por exemplo, maior robustez das plantas (Schifino-Wittmann e Dall'Agnol, 2001).

\section{CONCLUSÃO}

Através dos marcadores morfológicos utilizados é possível distinguir todos os híbridos das tangerineiras 'Clementina Fina' e 'Montenegrina'.
A época de maturação de frutos dos híbridos avaliados se estende do início de abril até o início de agosto, e a maioria destes aproxima-se mais da época de maturação do genitor feminino tangerineira 'Clementina Fina'.

Todos os híbridos avaliados e os genitores são diplóides, com número cromossômico $2 \mathrm{n}=18$, e todos os híbridos avaliados podem ser utilizados como genitores masculinos devido à elevada viabilidade de pólen.

\section{AGRADECIMENTOS}

À Universidade Federal do Rio Grande do Sul por disponibilizar a Estação Experimental Agronômica para os trabalhos de campo. Ao Laboratório de Citogenética e Eletroforese do Departamento de Plantas Forrageiras e Agrometeorologia da UFRGS. Ao Conselho Nacional de Desenvolvimento Científico e Tecnológico (CNPq) e à Coordenação de Aperfeiçoamento de Pessoal de Nível Superior (CAPES) pelo apoio financeiro.

\section{REFERÊNCIAS}

AGARWAL, P.K. Cytogenetical investigations in Rutaceae V. Cytomorphology of the three intergeneric hybrids of Citrus and Poncirus. Cytologia, v.54, p.705-708, 1989.

AOAC INTERNATIONAL. Official methods of analysis of AOAC International. AOAC International: Washington, 2002.

BERNET, G.P.; BRAMARDI, S.; CALVACHE, D.; CARBONELL, E.A.; ASINS, M.J. Applicability of molecular markers in the context of protection of new varieties of cucumber. Plant Breeding, v.122, p.146-152, 2003. 
BORÉM, A. Melhoramento de espécies cultivadas. Viçosa: UFV, 2005. 969p.

BRUGNARA, E.C.; SCHIFINO-WITTMANN, M.T.; WEILER, R.L.; SCHWARZ, S.F. Ploidia e fertilidade de pólen em progênies de citros. Bragantia, v.67, p.599-602, 2008.

CARVALHO, S.I.C.; BIANCHETTI, L.B.; REIFSCHNEIDER, F.J.B. Registro e proteção de cultivares pelo setor público: a experiência do programa de melhoramento de Capsicum da Embrapa Hortaliças. Horticultura Brasileira, v.27, p.135-138, 2009.

CAVALCANTE, H.C.; SCHIFINO-WITTMANN M.T.; DORNELLES, A.L.C. Meiotic behaviour and pollen fertility in an open-pollinated population of 'Lee' mandarin [Citrus clementina $\mathrm{x}$ (C. paradise x C. tangerina)]. Scientia Horticulturae, v.86, p.103114,2000

CHEN, C.; LYON, M.T.; O'MALLEY, D.; FEDERICI, C.T.; GMITTER, J.; GROSSER, J.W.; CHAPARRO, J.X.; ROOSE, M.L.; GMITTER, F.J. Origin and frequency of $2 \mathrm{n}$ gametes in Citrus sinensis X Poncirus trifoliata and their reciprocal crosses. Plant Science, v.174, p.1-8, 2008.

COLLETA FILHO, H.D.; MACHADO, M.A.; TARGON, M.L.P.N. Analysis of the genetic among mandarins (Citrus spp.) using RAPD markers. Euphytica, v.102, p.133-139, 1998.

DAVIES, F.R.; ALBRIGO, L.G. Crop Production Science in Horticulture 2: Citrus. Ed. CABI: Wallingford, 1994. 254p.

DOMINGUES, E.T.; SOUZA, V.C.; SAKURAGUI, C.M.; POMPEU JÚNIOR, J.; PIO, R.M.; TEÓFILO SOBRINHO, J.; Souza, J.P. Caracterização morfológica de tangerinas do banco de germoplasma de citros do centro de citricultura Sylvio Moreira/ IAC. Scientia Agricola, v.56, p.197-206, 1999.

FAO. Dados agrícolas de FAOSTAT. Organización de las Naciones Unidas para la Agricultura y la Alimentación. Disponível em: http://faostat.fao.org/, 2009.

GOWER, J.C. A general coefficient of similarity and some of its properties. Biometrics, v.27, p.857-871, 1971.

GUERRA, M. Introdução à citogenética geral. Rio de Janeiro: Guanabara, 1988. 142p.

GUERRA, M.; PEDROSA, A.; BARROS E SILVA, A.E.; CORNELIO, M.T.M.; SANTOS, K.; SOARES FILHO, W.S.F. Chromosome number and secondary constriction variation in 51 accessions of a citrus germplasm Bank. Brazilian Journal of Genetics, v.20, p.489-496, 1997.
IBGE Anuário Estatístico Brasileiro. Disponível em: http://www.ibge. gov.br/home/estatistica/economia/pam/2008/default.shtm, 2008.

IBPGR. Descriptors for Citrus. Rome, 1988.

KOEHLER-SANTOS, P.; DORNELLES, A.L. C.; FREITAS, L.B. Characterization of mandarin citrus germplasm from Southern Brazil by morphological and molecular analyses. Pesquisa Agropecuária Brasileira, v.38, p.797-806, 2003.

KOLLER, O.C. Citricultura: laranja, limão e tangerina. Porto Alegre: Rigel, 1994. 446p.

OLIVEIRA, A.C.; MACHADO, M.A. Resgate in vitro de embriōes de Tangor 'Murcote' (Citrus reticulata Blanco x C. sinensis (L.) Osbeck) e Laranja 'Pera' (C. sinensis (L.) Osbeck) e identificação de híbridos através de marcadores morfológicos e Moleculares. Genetic Molecular Biology, v.23, p.515, 2000.

OLIVEIRA, A.C.; NOVELLI, V.M.; GARCIA, A.N.; CRISTOFANI, M.; MACHADO, M.A. Identification of citrus hybrids through the combination of a leaf apex morphology and SSR markers. Euphytica, v.128, p.397-403, 2002.

RODRIGUES, J.C.V.; MACHADO, M.A.; CARVALHO, A.S.; Microscopia eletrônica de varredura de pólen de algumas espécies de Citrus e gêneros correlatos. Revista Brasileira de Fruticultura, v.20, p.382-386, 1999.

ROHLF, F.J. NTSYS pc: numerical taxonomy and multivariate analysis system. New York: Exeter Software, 2000.

SARTORI, I.A.; SCHÄFER, G.; SCHWARZ, S.F; KOOLER, O.C. Épocas de maturação de tangerinas na Depressão Central do Rio Grande do Sul. Revista Brasileira de Fruticultura, v.20, p.313-322, 1998.

SCHIFINO-WITTMANN, M.T.; DALL'AGNOL, M. Gametas não-reduzidos no melhoramento de plantas. Ciência Rural, v.31, p.169-175, 2001.

SIMIONI, C.; SCHIFINO-WITTMANN, M.T.; DALL'AGNOL, M.; GUERRA, D. Selection for increasing $2 \mathrm{n}$ gametes production in red clover. Crop Breeding and Applied Biotechnology, v.4, p.477-483, 2004.

SYBENGA, J. Cytogenetics in Plant Breeding. Springer: Berlin, 1993. 469p.

SYBENGA, J. Forty years of cytogenetics in plant breending: a personal view. In: LELLEY, T. (Ed.). Current topics in plant cytogenetics related to plant improvement. Vienna: Universitäts Verlang, 1998. p.22-32. 